\title{
HEROÍSMO, MÍDIA E DESEMPENHO ESPORTIVO: UM ESTUDO DO CASO ACERCA DA PRESENÇA DE RONALDO "FENÔMENO" NO CAMPEONATO PAULISTA DE 2009¹
}

\author{
Everton De Albuquerque Cavalcanti \\ Universidade Federal do Paraná, Curitiba, Paraná, Brasil \\ André Mendes Capraro \\ Universidade Federal do Paraná, Curitiba, Paraná, Brasil
}

\begin{abstract}
Resumo
O objetivo deste artigo foi analisar como a Folha de São Paulo retratou a imagem de Ronaldo no Campeonato Paulista de 2009. As fontes constituíram-se pelo caderno de esportes da Folha de São Paulo, sendo a delimitação temporal entre o início do mês de março, quando Ronaldo começou a atuar em jogos do Campeonato Paulista e o início do mês de maio, logo após o título. Tal escolha justificase devido ao objetivo da análise tratar do tema no intervalo de tempo em que a competição ocorria. A análise de conteúdo de Bardin serviu de técnica metodológica para análise do material empírico. Em caráter conclusivo, notamos que o periódico foi um meio propício para construção da memória esportiva, acentuando o mito do herói, pois relembrava feitos passados como forma de consolidar os fatos do presente. Tal representação heroica é retratada por meio de características discursivas interligadas à emoção e à polêmica.
\end{abstract}

Palavras-chave: Futebol. Herói. Mídia.

\section{Introdução}

Historicamente, o futebol passou por transformações que o consolidaram como elemento significativo da cultura brasileira. Essa caracterização como algo implícito ao Brasil, somada ao processo de globalização e à forte inserção na indústria de entretenimento, proporcionaram o que denominamos de espetáculo esportivo (PRONI, 1998).

Essa mercantilização adaptou as características que identificam o futebol brasileiro às práticas comerciais de promoção e divulgação do esporte (DAMO, 2001; GASTALDO, 2000; GURGEL, 2009). Tais ações advêm de uma relação amalgamada entre os agentes que conduzem o futebol, utilizando-se do sentimentalismo que afeta o público que gosta do esporte, para atender interesses econômicos de quem investe nesse segmento (CAVALCANTI, 2013).

Tal mercantilização do futebol fomentou modificações estruturais na forma de se conduzir e de administrar o esporte. $\mathrm{O}$ fortalecimento da relação entre o campo esportivo com o político, o econômico, o social e o cultural (BOURDIEU, 1983), permitiu como interesse em melhor compreender como os setores gestores do futebol organizam o mesmo, possibilitando o amadurecimento das reflexões que ampliaram a produção histórico/social no subcampo futebolístico (RIBEIRO, 2012).

Nesse contexto, a mídia enquadra-se como um meio propício à divulgação da informação (BORELLI, 2001), à construção discursiva de acordo com a ideologia de sua instituição (BOURDIEU, 1996) e à influência geral na formação de opinião. Proporcionando

\footnotetext{
${ }^{1}$ Apoio e financiamento CAPES.
} 
celeumas que afetam o imaginário do torcedor por meio da emoção, da polêmica e da subjetividade na narrativa (COSTA, 2010).

Uma das maiores construções discursivas emergidas da relação entre mídia e futebol é a figura do herói que, segundo Campbell (1997), caracteriza-se como o sujeito que perpassa dificuldades na busca pelo objetivo, supera obstáculos e consolida-se com a conquista almejada. Nessa mesma linha, Rúbio (2001) afirma que o herói constitui uma representação que enquadra o atleta como modelo de conduta social, aproximando-o de sujeitos que se identificam com sua realidade cotidiana.

O objetivo do artigo é analisar e discutir como a Folha de São Paulo retratou a imagem de Ronaldo no Campeonato Paulista de 2009, sendo esta a primeira competição do atleta ao retornar ao futebol brasileiro após mais de um ano de inatividade profissional. Para tanto, cria-se a hipótese de que a relação entre a forma de veiculação da imagem de atletas representativos - como Ronaldo - pode afetar a formação da opinião dos apreciadores do esporte e também do senso comum, além de movimentar as práticas comerciais interligadas aos agentes envolvidos no contexto.

As fontes históricas analisadas foram constituídas pelas matérias publicadas no Caderno de Esportes da Folha de São Paulo, considerada um dos veículos de comunicação impresso/online de maior repercussão e circulação no Brasil. Esse periódico está diariamente disponível nas bancas de jornal, também por meio de assinatura mensal e na internet através do portal UOL (MOREIRA: MARCHI JUNIOR, 2009). O periódico apresenta nove sessões Opinião, Política, Mundo, Economia, Cotidiano, Esporte, Cultura, F5 e Classificados - com volume médio de 250 matérias diárias pelo sistema de atualização minuto a minuto.

A delimitação temporal foi entre o início do mês de março, quando Ronaldo começou a atuar em jogos do Campeonato Paulista pelo Sport Club Corinthians Paulista e o início do mês de maio, logo após o clube ter conquistado o campeonato, totalizando 26 matérias entre capas, reportagens e crônicas, com o atleta sendo o foco principal ou secundário no material coletado. Portanto, o termo "Ronaldo" foi utilizado como principal critério de busca das matérias.

Utilizou-se da proposta metodológica da análise de conteúdo de Bardin (1977), que propõe:

\begin{abstract}
Um conjunto de instrumentos metodológicos cada vez mais subtis em constante aperfeiçoamento, que se aplicam a "discursos" (conteúdos e continentes) extremamente diversificados. O fator comum destas técnicas múltiplas e multiplicadas - desde o cálculo de frequências que fornece dados cifrados, até a extracção de estruturas traduzíveis em modelos - é uma hermenêutica controlada, baseada na dedução: a inferência. Enquanto esforço de interpretação, a análise de conteúdo oscila entre os dois pólos do rigor da objectividade e da fecundidade da subjectividade (BARDIN, 1977, p. 9).
\end{abstract}

De acordo com os preceitos de Bardin (1977), foi possível definir as categorias que predominavam nas matérias da Folha de São Paulo. A saber: heroísmo, inserção midiática (especificamente no tangente a própria Folha de São Paulo) e desempenho esportivo.

Balizando a análise do material coletado, foi utilizada a teoria do mito do herói de Campbell (1997), a qual se define como um ciclo no qual o herói atravessa o limiar da aventura, superando desafios, perpassando obstáculos intransponíveis, conquistando a vitória e retornando ao limiar, trazendo a seu povo as experiências do triunfo. Subdividiram-se as análises em dois momentos, primeiramente focando nas fontes referentes à primeira fase do Campeonato Paulista e, posteriormente, nas referentes às semifinais e às finais da competição. 


\section{O herói em foco: as narrativas preliminares}

Superar os próprios limites passa a figurar como secundário quando se entende que a transposição do adversário é um dos pilares para o sucesso no futebol, associado à indústria cultural e de entretenimento. Esse preceito é chave para a identificação do discurso midiático como uma construção elaborada a partir de fundamentos que priorizam determinados interesses, sobretudo, da imprensa própria e do aspecto comercial presente no campo esportivo (GASTALDO, 2009).

Vitórias e conquistas identificam o herói esportivo como modelo de referência (CAMPBELL, 1997). Essa imagem construída a partir de histórias de vida que, por sua vez, são (re)elaboradas, tornando-se, então, representações sociais; processo cuidadosamente estruturado por meio de estratégias publicitárias, cujo objetivo é o de atrelar uma marca ao herói exposto pelos meios de comunicação (COSTA, 2010).

No sentido de dispor a imagem de Ronaldo como parte dessa indústria futebolística, a Folha de São Paulo destacou a vitória do Corinthians frente à Associação Desportiva São Caetano, quando Ronaldo marcou os dois tentos do time paulista na partida. Enfatizou-se na reportagem que as comemorações discretas do atacante pareciam demonstrar sua outrora habitualidade com o ofício de artilheiro (GALDIERI: BUENO, 12 mar. 2009, p. D1).

Aproveitando-se do contexto, - aquele de euforia da estreia - a narrativa visava comparar o atual momento do atleta com o do passado, no qual Ronaldo foi referência no cenário futebolístico. Tais comparações consolidam a figura heroica, a partir do resgate da própria trajetória do esportista, fomentando o sentimento de esperança por novos êxitos (CAPRARO et al., 2011).

O jornalismo interligado ao futebol apresenta-se, nesse sentido, como um relevante veículo de "construção da memória", que visa relembrar a história de vitórias, conquistas, fracassos, imagens e fatos, colaborando para a criação de identidades, que aproximam os feitos do passado com a situação das práticas sociais do presente (HELAL; SANTORO; SOARES, 2004).

A construção das narrativas, a partir da imprevisibilidade do futebol, torna-se uma estratégia que coloca o presente em continuidade com o passado, criando elos identitários entre gerações e consolidando o esporte como um espaço de dramatização, que reafirma identidades a partir do processo de espetacularização (SOARES, 2007).

Aos 5 min, em sua primeira participação, também de primeira, de direita, pegou seco na bola molhada o cruzamento de Dentinho e virou o jogo. Pronto! Em sua segunda partida no Pacaembu, Ronaldo fazia um pouco mais de história, agora sem derrubar nenhum alambrado, mas fazendo até o que não fez em Presidente Prudente, fazendo chover (KFOURI, 12 mar. 2009, p. D3).

A narrativa refere-se a uma crônica ainda acerca da partida frente ao São Caetano. O detalhamento na descrição da performance em campo demonstra o caráter folhetinesco do gênero, no entanto, atenta também para a continuidade na discussão da vitória, como mantenedora do status quo no esporte moderno (COSTA, 2010). É visível o quanto o transcurso da partida colaborou para que o jornal se utilizasse do drama, do heroísmo, da memória e da espetacularização, no sentido de construir um discurso comercializável e compatível com a cultura esportiva contemporânea (RÚBIO, 2006).

Ao longo das primeiras partidas em que atuou, o rendimento de Ronaldo oscilou bastante. Consequentemente, as análises da Folha de São Paulo acompanharam tal oscilação, já que o jornal em geral, por pregar a objetividade, acaba sendo extremamente descritivo e simplista, atribuindo ao jogador apenas um papel: o de ser finalizador. 
Tal situação pode ser observada quando o periódico teceu críticas à atuação de Ronaldo no clássico com o Santos Futebol Clube, o jornal afirmou: "Ronaldo não fez o que mais se espera dele" (FOLHA DE SÃO PAULO, 23 mar. 2009, p. D1). Já na partida com a Associação Atlética Ponte Preta, o jornal mudou o discurso, elogiando o atleta, ao afirmar: "Ronaldo fez ontem tudo o que a torcida do Corinthians espera dele" (GALDIERI, 26 mar. 2009 , p. D2). Não se trata aqui de pinçar manchetes a fim de corroborar com uma ideia, mas de facilitar a visualização de generalidades que o contexto propõe e o jornal se utiliza.

$\mathrm{O}$ interesse do jornal em retratar as atuações de Ronaldo, mesmo que essa se contraponha ao resultado da partida, demonstra seu potencial midiático no universo futebolístico. Além do que, o periódico corrobora com a ideia de que a construção do discurso vai ser elaborada a partir da imagem apriorística dos sujeitos, priorizando aqueles que potencializam mais a comercialização do esporte (CAPRARO et al., 2011).

No entanto, o exemplo também ressalta que o desempenho atlético abaixo do esperado não apresenta vínculo com o da equipe, o que pode ser um dos motivos para uma constante responsabilização individualizada pelos fracassos de repercussão nacional. O heroísmo e o vilanismo são paralelos nesse processo do discurso esportivo, e a tensão para um dos lados aparenta depender exclusivamente do resultado do desempenho momentâneo do atleta (COSTA, 2008).

Sendo assim, o capital simbólico de Ronaldo no campo esportivo o consolida como um sujeito capaz de atrair a atenção midiática, independentemente do momento pelo qual o atleta passa. As estratégias de elaboração da notícia variam de acordo com o sucesso ou fracasso, no entanto, a consolidação da imagem como um produto da indústria do entretenimento dificilmente será afetada devido a sua trajetória no esporte (CAVALCANTI; CAPRARO; SOUZA, 2011).

A imprevisibilidade constitui parte significativa da criação de identidades, que permeiam o futebol pela lógica de consumo (HELAL; SANTORO; SOARES, 2004). Além disso, possibilita a aproximação com o ideal do herói esportivo, que supera obstáculos, conquista, fracassa, reergue-se e retorna ao caminho das vitórias (RÚBIO, 2001; CAMPBELL, 1997; MULLER, 1987). A oposição entre um fato e outro, na mesma semana, pode até mesmo fazer parte de uma estratégia discursiva que objetivava afetar os leitores por meio da elaboração de um discurso que se aproveitava desta constante oscilação de rendimento, utilizando-se da memória para enaltecer, polemizar e dramatizar (COSTA, 2011).

\section{A representação heroica e a supervalorização da vitória}

Temos que atacar e ferir o São Paulo. Fazer deste jogo [o de amanhã, o primeiro entre os times nas semifinais do Paulista] um jogo muito difícil para eles. Temos que pressioná-los em seu campo. Temos que fazer gols, porque o São Paulo tem a vantagem de jogar por dois empates (BUENO, 11 abr. 2009, p. D3).

A Folha de São Paulo descreve um discurso de coragem do atleta, que demonstrava ter uma estratégia definida para a disputa. Expressões como: "atacar", "ferir" e "pressionar", tentam utilizar do heroísmo clássico - aquele do guerreiro, soldado ou lutador - usado como metáfora no esporte, já que se tratava de identificar o esportista como um sujeito que não desiste do objetivo (CAPRARO et al., 2011).

A busca pelas vitórias remete às experiências nas quais o candidato a herói demonstraria as suas habilidades e condições para ser um atleta de destaque (RÚBIO, 2001). O empenho, a coragem, a destreza e a responsabilidade, detalhadas pelas notícias sobre o atleta, podem colaborar na identificação heroica com o desafio (MULLER, 1987).

Compreende-se, então, que as histórias construídas pela imprensa esportiva inserem-se na definição do conceito de tradições inventadas, já que o cenário aparentava modificar-se 
constantemente, sendo os fatos noticiados de maneira a suprir interesses comerciais, amalgamados entre o campo esportivo e a cultura de mídia (SANTOS; CAPRARO, 2012).

Logo, entende-se que o enaltecimento dos atletas com potencial midiático trata-se de uma estratégia que visa atingir o leitor pelo carisma, pela trajetória dificultosa, pelas vitórias, pelas conquistas e pela capacidade - dos responsáveis pela imagem do esportista - de manter o consumidor interessado no futebol espetáculo (CAVALCANTI, CAPRARO, SOUZA, 2011; SILVA, 2010).

Em outra notícia, o periódico dedicou-se a relatar as dificuldades enfrentadas por Ronaldo, no clássico frente ao São Paulo, válido pelo primeiro confronto da semifinal do Campeonato Paulista, justificando sua atuação sem destaque como mérito do adversário. $\mathrm{O}$ jornal afirmou que no jogo mais complicado desde seu retorno ao futebol, o atacante não teve oportunidades de gol e foi bem marcado pela defesa adversária (FOLHA DE SÃO PAULO, 13 abr. 2009, p. D6).

A jornada heroica proporciona experiências práticas que conduzem o sujeito ao autoconhecimento, como o controle da ansiedade, da angústia e do medo (MULLER, 1987). $\mathrm{O}$ atleta com trajetória repleta de situações que exigiram tomadas de decisão torna-se capaz de assumir tal responsabilidade perante o campo esportivo, tendo sua imagem, consequentemente, associada à figura capaz de decidir uma partida.

Segundo o periódico, no segundo confronto pela semifinal, o atleta foi o destaque positivo da partida. Após um primeiro tempo discreto, iniciou a jogada do primeiro gol marcado por Douglas - e marcou o segundo em uma arrancada característica que relembrou os melhores momentos de sua trajetória no futebol (GALDIERI; ASSIS, 20 abr. 2009, p. D1).

Após a vitória sobre o São Paulo, a atuação de Ronaldo gerou o ressurgimento do atacante e do Corinthians no cenário esportivo, como exemplos vitoriosos. O periódico tenta realizar uma aproximação entre a instituição e o sujeito, já que a relação entre atleta e clube pode ser equiparada devido às dificuldades que tiveram que superar para retornar às conquistas (FOLHA DE SÃO PAULO, 20 abr. 2009, p. D3).

A comparação entre as dificuldades pelas quais os dois agentes perpassaram, antes de ressurgirem vitoriosamente no cenário futebolístico brasileiro, correlaciona-se também ao processo histórico pelo qual passaram ao longo do tempo. A instituição caracterizada, pelo senso comum e por seus torcedores, como geradora do sentimento de sofrimento, conjuga-se com a constante exposição do esportista nos meios de comunicação, como superadora de obstáculos (NEGREIROS, 2010; RÚBIO, 2001).

É possível deduzir que a parceria entre Corinthians e Ronaldo iniciou-se - entre outros motivos - pela compatibilidade de perfil, construída e veiculada pela mídia em interface com as exigências do campo esportivo. O periódico aproveitou-se dessa relação de aproximação das características entre os agentes, elaborando um discurso que explicitava ainda mais a interdependência entre os supostos "ressurgimentos" do clube e do atleta.

O processo de mitificação, a partir da descrição dos detalhes da partida entre Corinthians e São Paulo, pode ser observado por meio da elaboração da narrativa. Segundo o jornal, o triunfo corintiano consumou-se após o gol de Ronaldo, terminando com as chances do adversário na disputa, que contou com o apoio de mais de 40 mil torcedores no estádio do Morumbi (FOLHA DE SÃO PAULO, 20 abr. 2009, p. D3).

A descrição, a colocação do discurso e a busca por afetar o imaginário esportivo pela metanarrativa que enaltece o herói, que sustenta as celebridades, que reelabora o cenário do futebol e que constrói a identidade nacional (RÚBIO, 2001), demonstram como determinados esportistas, presentes na mídia, mostram-se capazes de modificar ou consolidar práticas sociais referentes à indústria de entretenimento (DAMO, 2008).

Além do enaltecimento aos feitos heroicos como forma de aumentar o consumo do jornal, o não esmorecimento (mesmo com o constante sofrimento) é outra categoria utilizada 
para retratar a imagem do atleta em "batalha". Segundo o periódico, Ronaldo sofreu com a marcação adversária e não teve facilidade na disputa com os zagueiros são-paulinos (FOLHA DE SÃO PAULO, 2009, p. D3).

Essa estratégia discursiva, que utiliza o sofrimento para enaltecer as conquistas esportivas, é outro motivo que torna o futebol parte substancial de uma cultura de entretenimento espetacularizada. Sempre que o jornal noticiou as dificuldades enfrentadas na busca por vitórias, a emoção e a comoção tornaram-se também temas recorrentes, haja vista que os sujeitos da sociedade contemporânea se identificam com esse tipo de comportamentos (BITENCOURT et al., 2005).

Com a vitória do Corinthians sobre o São Paulo, o periódico aproveitou-se do momento para correlacionar o enaltecimento pela vitória com o sentimentalismo memorialístico. Expressões como "gênio", "dono do jogo", "artilheiro" e "diferenciado" definiam Ronaldo como responsável direto pela classificação do Corinthians para a final do Campeonato Paulista de 2009 (COELHO, 20 abr. 2009, p. D3; FOLHA DE SÃO PAULO, 21 abr. 2009, p. D4).

Tal narrativa acentuava a existência de uma relação sólida entre o heroísmo e o sofrimento, já que a busca por vitórias está interligada aos sacrifícios que o sujeito deve ser capaz de fazer para alcançar a dádiva das conquistas (CAMPBELL, 1997; MULLER, 1987;).

Um exemplo da valorização dos feitos esportivos, independentemente do nível competitivo de disputa, é a comparação do desempenho em gols de Ronaldo no Corinthians e em clubes como Real Madrid, Milan e Internazionale de Milão. O jornal afirmou que a média do atleta no clube paulista é superior ao período em que permaneceu nas equipes europeias citadas (COBOS, 23 abr. 2009, p. D4).

No entanto, vale ressaltar que os números absolutos utilizados na notícia são de nove partidas e seis gols, marca insignificante de acordo com o período de atuações no Real Madrid, por exemplo. Tal análise reflete a utilização dos dados de acordo com os interesses do próprio jornalista, corroborando com a ideia de que por vezes a mídia utiliza-se de estratégias que favoreçam a comercialização da notícia (COSTA, 2010). Reforça-se, assim, a ideia de que a mercantilização do esporte atrelada à subjetividade da notícia proporciona, por vezes, a manipulação de dados quantitativos que objetivam favorecer e consolidar uma cultura midiática de consumo (DAMO, 2008).

O sujeito que se destaca ao enfrentar o desconhecido, o novo e o extraordinário, é identificado pela sociedade como o responsável pelos anseios e interesses da comunidade a qual representa (MULLER, 1987). Nesse sentido, o jornal destacou: "Ronaldo fez a diferença: atacante marca dois gols na vitória contra o Santos e recebe elogios de Pelé" (FOLHA DE SÃO PAULO, 27 abr. 2009, p.1).

Há uma categorização da expressão "fazer a diferença", constantemente utilizada pelo jornal na elaboração de narrativas relacionadas ao atleta, que aponta para uma discussão que permeia a figura heroica: seria por meio da inteligência, da habilidade e da competência que os feitos eram possíveis ou apenas porque o herói teria talento? Valendo a ressalva de que a ideia de talento (genialidade artística) é uma das características mais atribuídas à formação identitária do futebol brasileiro (HELAL, 2003).

A narrativa apresentou no caso uma abordagem que seguiu a mesma máxima que explica o desempenho com excelência dos atletas brasileiros: o talento trata-se de uma característica considerada natural, inata, particular, singular, como se o sujeito nascesse com a dádiva para a prática futebolística (GIGLIO, 2007).

Tal discurso contrapõe-se ao herói batalhador, superador de obstáculos - aquele que caracteriza os heróis clássicos. No entanto, uma abordagem não anula a outra, apenas ratifica a ideia de que o jornal é um veículo de comunicação propício a constantes mudanças na utilização das estratégias discursivas; e que a variação na construção da notícia pode ser 
oriunda da necessidade de adaptar-se à cultura nacional (sem abrir mão dos interesses da cultura de mídia).

O jornal, então, descreveu de maneira espetacularizada que na etapa final da partida entre Corinthians e Santos, Ronaldo fez um gol histórico na Vila Belmiro. Relatou-se, ainda, que Ronaldo teve um dia de rei na casa de Pelé, o qual elogiou o gol do atacante, comparando-o consigo mesmo (GALDIERI; CALCIOLI, 27 abr. 2009, p. D1; BUENO, 27 abr. 2009, p. D3).

Graças aos pés de Ronaldo, o Corinthians está prestes a colocar as mãos no Paulista. Com atuação precisa, o fenômeno fez a diferença entre um empate, que já seria bom resultado, e a vitória que deixa os corintianos separados da taça do estadual apenas por um desastre no próximo domingo (GALDIERI, CALCIOLI, 27 abr. 2009, p. D1).

A expressão "fenômeno" remete novamente à discussão do dom como algo inato ao sujeito (GIGLIO, 2007). Tal "alcunha" surgiu na Itália devido à impressão causada pela capacidade do atleta em ser decisivo, utilizando-se de habilidades que, segundo a própria Folha de São Paulo, fizeram a diferença na partida entre Corinthians e Santos.

Embora tudo favorecesse ao clima de euforia fomentado pelo periódico, não se pode desconsiderar a influência que a trajetória do atleta (RÚBIO, 2001) tinha na construção da imagem positiva elaborada a seu respeito. A utilização da alcunha "fenômeno" é um exemplo de como os feitos passados de Ronaldo afetaram a maneira com que a sua figura foi retratada no jornal.

Essa categorização a respeito do desempenho atlético continuou a ser retratada e mitificada por parte do jornal: "Pelé já concedeu a honraria de uma placa em seu templo a Marcelinho Carioca, que nunca chegou perto da majestade de Ronaldo mundo afora" (BUENO, 27 abr. 2009, p. D3).

A expressão "majestade", utilizada para descrever o jogador na notícia, remete ao tratamento pessoal destinado a rei e rainha. Neste caso, além de atribuir a Ronaldo o termo comumente referenciado a Pelé, existiam outras características que interligavam o heroísmo às responsabilidades de um "reinado". A coragem, a persistência, a ousadia e a sabedoria são qualificações inerentes àqueles que se identificam como referência de uma sociedade (MULLER, 1987; RÚBIO, 2001).

Pontualmente, o jornal relembrou os feitos do atleta ao longo da trajetória no Campeonato Paulista. Por exemplo: o gol contra o Palmeiras, que definiu o empate no clássico da primeira fase; ou o gol na partida frente ao São Paulo, no estádio do Morumbi, válido pelas semifinais. Faltava apenas marcar um gol no Santos de Pelé (GALDIERI; CALCIOLI, 27 abr. 2009, p. D3). A rivalidade mostra-se como um dos fatores mais importantes na formação da narrativa jornalística. O periódico definiu tais exemplos, objetivando afetar o imaginário torcedor através da emoção causada por superar um rival, sentimento que identifica Ronaldo como herói da comunidade corintiana.

O jornal, portanto, é um dos responsáveis pela construção, desconstrução e reconstrução da figura heroica (MARQUES, 2005). Situação que permite compreender a oscilação na formação discursiva, determinada pelo contexto social e interesses tácitos, tanto da cultura midiática quanto do próprio campo esportivo (COSTA, 2010).

A repercussão do desempenho de Ronaldo (e as suas valências heroicas) rendeu até uma nova discussão acerca do retorno do atleta à seleção brasileira. O jornal relatava que, após a atuação no clássico e o gol antológico que decidiu a partida, Ronaldo voltou a pensar na possibilidade de ser convocado (ASSIS, 28 abr. 2009, p. D1).

A repercussão era proporcional ao status do esportista no meio futebolístico. Tal constatação justifica o posicionamento do jornal em questionar o tema (HELAL; SOARES, 
2001), já que Ronaldo teve inúmeras passagens pelo selecionado nacional, o que, teoricamente, embasaria um possível retorno na época.

Em outra notícia, a Folha de São Paulo relatou e demonstrou através de dados quantitativos que, após a chegada de Ronaldo ao Corinthians, o clube deixou de perder clássicos regionais com frequência e disputa o título paulista com possibilidade de conquistálo de forma invicta, o que não ocorria desde 1972:

A partir de 2004, quando iniciou seu jejum no Estadual, até a estreia do atacante, o Corinthians enfrentou seus três maiores rivais pelo torneio (Palmeiras, Santos e São Paulo) 14 vezes. Só venceu um desses jogos. Contando o Brasileiro, foram 34 clássicos desde 2004, e só sete triunfos corintianos. Números que passaram de ridículos à impressionantes depois de que o camisa 9 entrou em campo pelo clube. Foram cinco clássicos, com quatro vitórias e um empate (COBOS, 03 mai. 2009, p. D1).

Tais reflexões - além de atenderem à tendência à quantificação, característica fomentada pela cultura esportiva norte-americana - enaltecem algumas características que remetem o esportista a condição de herói esportivo. Destaca-se: a ousadia, definida pela coragem cautelosa, sem a qual não haveria busca por desafios, nem, consequentemente, a superação de conflitos (MULLER, 1987).

A ousadia é uma das características constantemente atribuídas ao jogador de futebol brasileiro, enquadrando-se, portanto, na própria definição do herói esportivo, tanto no que concerne às discussões acerca do dom inato, quanto na correlação com o mito superador de obstáculos.

Tal conceito, implícito à forma de jogar, pode ser também associado ao estilo de vida brasileiro. A ousadia emaranha-se à irreverência, à malandragem, à imprevisibilidade características que compõem o cenário futebolístico e identificam tanto a sociedade brasileira, quanto o futebol (GIGLIO, 2007).

O que o jornal tenta retratar, na correlação entre a chegada do atleta ao Corinthians e o fato de o clube ter deixado de ser - nas palavras contundentes da imprensa especializada "saco de pancadas" em clássicos, é o enaltecimento do jogador por algo que pode ser apenas uma coincidência. Entretanto, é narrado no sentido de atribuir ao herói a ousadia vinculada à coragem por realizar feitos notáveis, que afetam o meio esportivo contemporâneo e criam um forte vínculo identitário com a sua torcida.

O jornal, então, avalia a possibilidade de Ronaldo conquistar o primeiro título pelo Corinthians em um estádio (Pacaembu) com a capacidade máxima de público, ou seja, lotado - outra marca registrada de sua volta ao futebol brasileiro (FOLHA DE SÃO PAULO, 03 mai. 2009, p. D6b). A notícia avalia um dos ganhos comerciais que a imagem do esportista trouxe ao clube. Segundo o jornal, a frequente ocupação máxima do estádio relaciona-se ao fato de Ronaldo estar atuando em nível competitivo. Tal perspectiva corrobora com a ideia de que o futebol é um local de difusão de identidades sociais enraizadas no imaginário do torcedor.

A indústria do entretenimento, por vezes, exige do espetáculo esportivo a atribuição da responsabilidade pelo feito ao herói (RÚBIO, 2001). Esse se identifica com o público por meio da sua personalidade humana, porém, singulariza-se por sua natureza heroica e condutora do objetivo de sua comunidade (CAMPBELL, 1997).

Tal reflexão apresenta o heroísmo como um meio propício para o desenvolvimento de uma cultura esportiva centrada no atleta. As próprias narrativas do jornal conduzem o discurso no sentido de atribuir ao esportista os resultados de um processo, que envolve maior complexidade para o seu entendimento (COSTA, 2010). A presença do atleta influencia no fato de o estádio frequentemente atingir sua capacidade máxima de público. Entretanto, tal 
aspecto não se resume à forma como o discurso é retratado pelo periódico, haja vista o futebol contemporâneo se tratar de uma relação comercial, que objetiva atingir o interesse de diversos setores de mercado.

Outras demonstrações desta categorização dos fatos na figura do jogador podem ser observadas nas narrativas expostas antes e após a segunda partida da final do Campeonato Paulista contra a equipe do Santos. O periódico relatou que a faixa de campeão destacava o nome do atacante e que, depois do anúncio do placar eletrônico, a torcida comemorou sua presença na partida como se fosse um gol (DUARTE, 04 mai. 2009, p. D6).

Ronaldo será a grande estrela na festa de encerramento do Paulista, hoje, em casa de shows na zona sul. O corintiano receberá homenagem especial por sua volta ao futebol. A FPF espera que Lula faça a entrega da taça e também dê as congratulações ao fenômeno (ARRUDA, 4 mai. 2009, p. D2).

Tal estratégia de centralização do evento midiático no atleta tornou-se repetitiva nas matérias, ainda mais com a possibilidade de enaltecimento da vitória, tentativa explícita de gerar maior identificação do público com a figura heroica e consolidação do cenário de superação, constantemente retratado pela mídia ao longo da trajetória de Ronaldo (CAVALCANTI, CAPRARO, SOUZA, 2011).

As homenagens enfatizadas pela cobertura do jornal demonstram a representação social criada em torno do atleta. Tal capital simbólico, conquistado ao longo da carreira, é consolidado pela cultura midiática que supervaloriza a vitória (COSTA, 2011). O retrato de superação, de coragem e de persistência fomenta um sentimento de identificação por parte daqueles que passaram por dificuldades semelhantes àquelas as quais Ronaldo se submeteu (RÚBIO, 2010).

\section{Considerações finais}

A partir da problemática inicial, pode-se concluir que o jornal se trata de um meio propício para construção da memória esportiva, relembrando feitos heroicos como forma de consolidar um ideário vinculado ao presente. Tal representação do herói é retratada por características discursivas interligadas à emoção e à polêmica.

O capital simbólico do qual o atleta é detentor o condiciona a responder como principal artífice da situação vivenciada pela equipe, sendo assim, o mesmo é identificado como referência social e esportiva devido à sua trajetória no futebol. Em determinados momentos ocorre a descrição de uma narrativa folhetinesca na Folha de São Paulo, pois, por meio de um discurso teatralizado, Ronaldo torna-se o protagonista, independentemente do contexto apresentar-se favorável ou desfavorável ao atleta.

Essa narrativa, a princípio, não é intencional e justamente oscila de acordo com a efemeridade do jornal. Logo, interessam ao periódico os sujeitos dotados de representatividade no cenário esportivo para que o discurso se legitime no senso comum. Essa relação entre o futebol e a indústria cultural de entretenimento utiliza da identificação do esporte com a paixão torcedora para atrelar tal sentimento às diversas práticas comerciais desenvolvidas no campo esportivo.

Outros discursos relacionados ao sentimentalismo implícito nas práticas futebolísticas puderam ser observados nas narrativas. O sofrimento que permeia o cotidiano do herói e a luta por suas conquistas aparentam estar relacionados aos obstáculos perpassados pelos sujeitos identificados com o esporte. Há uma transposição da superação das dificuldades heroicas, pois estas retratam simbolicamente o protagonista e sua saga pela vitória em um mundo marcado pela competição. 


\title{
HEROISM, MEDIA AND SPORT PERFORMANCE: A CASE STUDY OF RONALDO "PHENOMENON" IN SÃO PAULO CHAMPIONSHIP 2009
}

\begin{abstract}
The purpose of this article was to analyze how the Folha de São Paulo portrayed the image of Ronaldo in the Championship 2009. The sources constituted by the sports section of Folha de São Paulo, with the temporal distinction between the beginning of March when Ronaldo began acting in the Championship games and the beginning of May, after the title. This choice is justified by the objective of the analysis address the issue in the time frame in which the competition occurred. The Bardin content analysis served as a methodological technique for analysis of the empirical material. In a conclusive nature, it is noticed that the journal was a suitable way for the construction of sports memory, emphasizing the hero myth, as recalled past made as a way to consolidate the facts of the present. This heroic representation is portrayed through discursive characteristics linked to emotion and controversy.
\end{abstract}

Keywords: Football. Hero. Media.

\section{HEROÍSMO, MEDIOS DE COMUNICACIÓN Y RENDIMIENTO DEPORTIVO: UN ESTUDIO DE CASO SOBRE LA PRESENCIA DE RONALDO "FENÓMENO" EN EL CAMPEONATO PAULISTA DE 2009}

\section{Resumen}

El propósito de este artículo fue analizar de qué modo la Folha de São Paulo retrató la imagen de Ronaldo, en el campeonato de 2009. Las fuentes constituidas por la sección de deportes del periódico Folha de São Paulo se delimita temporalmente entre el inicio de marzo, cuando Ronaldo comenzó a actuar en los partidos del campeonato, y principios de mayo, después del título. Esta elección se justifica porque el objetivo de análisis es tratar el tema durante el período temporal en que aconteció la competición. El análisis de contenido de Bardin sirvió como técnica metodológica para el análisis del material empírico. Concluimos que la revista fue un medio adecuado para la construcción de la memoria deportiva, enfatizando el mito del héroe, pues recordaba hechos pasados como forma de consolidar hechos del presente. Esta representación heroica se retrata a través de las características discursivas vinculadas a la emoción y la controversia.

Palabras-clave: Fútbol. Héroe. Medios de Comunicación.

\section{Referências}

ARRUDA, E. Convidado especial. Folha de São Paulo. São Paulo, 04 maio 2009. p. D2.

ASSIS, T. Vontade é igual à de 2002, diz Ronaldo. Folha de São Paulo. São Paulo, 28 abr. 2009. p. D1.

BARDIN, L. Análise de Conteúdo. Lisboa: Edições 70, 1977.

BITENCOURT, F. G.; HACK, C.; COSTA, A. G.; RIBEIRO, S. D.; LISBÔA, M.; MÓL, M.; MEZZAROBA, C.; MENDES, D.; PIRES, G. Ritual olímpico e os mitos da modernidade: implicações midiáticas na dialética universal/local. Pensar a Prática, Goiânia, v.8, n.1, p. 21 -36, jan./jun., 2005.

BORELLI, V. Cobertura midiática de acontecimentos esportivos: Uma breve revisão de estudos. In: Intercom/2001 - Congresso Brasileiro de Comunicação, 24. Campo Grande, 2001, Anais... p. 1-15, 2001, Campo Grande. 
BOURDIEU, P. A economia das trocas linguísticas: O que falar quer dizer. São Paulo: Editora da Universidade de São Paulo, 1996.

BOURDIEU, P. Questões de sociologia. Rio de Janeiro: Marco Zero, 1983.

BUENO, R. Ronaldo vive dia de rei, na casa do rei. Folha de São Paulo. São Paulo, 27 abr. 2009. p. D3.

BUENO, R. 'Temos que ferir o São Paulo', afirma Ronaldo. Folha de São Paulo. São Paulo, 11 abr. 2009. p. D3.

CAMPBELL, J. O herói de mil faces. São Paulo: Editora Pensamento, 1997.

CAPRARO, A. M.; SCHELIGA, G.; CAVICCHIOLI, F.; MEZZADRI, F. A imagem do atleta: publicidade em ano de Copa do Mundo de Futebol (Alemanha - 2006). Revista Brasileira de Educação Física e Esporte, São Paulo, v.25, n.1, p.163-71, jan./mar. 2011.

CAVALCANTI, E. A. A mídia e o mito do herói: analisando as matérias do caderno de esportes da Folha de São Paulo a partir do caso Ronaldo (2008-2011). 2013. 135f. Dissertação (Mestrado em Educação Física) - Departamento de Educação Física, UFPR, Curitiba. 2013.

CAVALCANTI, E. A.; CAPRARO, A. M.; SOUZA, D. L. "Cai o pano": uma análise do encerramento da carreira de Ronaldo "fenômeno" a partir de duas mídias digitais esportivas. Movimento, Porto Alegre, v.17, n.3, p. 175-192, jul/set. 2011.

COBOS, P. No Brasil, Ronaldo fica ainda mais fenomenal. Folha de São Paulo. São Paulo, 23 abr. 2009. p. D4

COBOS, P. Ronaldo adoça busca do Corinthians pelo Paulista. Folha de São Paulo. São Paulo, 03 mai. 2009. p. D1.

COELHO, P. V. Três atacantes, que nada! Folha de São Paulo. São Paulo, 20 abr. 2009. p. D3.

COSTA, L. M. A trajetória da queda: as narrativas da derrota e os principais vilões da seleção brasileira em Copas do Mundo. 2008. 159 f.Tese (Doutorado em Letras) Departamento de Letras, UERJ, Rio de Janeiro. 2008.

COSTA, L. M. Futebol folhetinizado. A imprensa esportiva e os recursos narrativos usados na construção da notícia. Revista Logos - Comunicação e Esporte, Rio de Janeiro, v.17, n.2, 2. sem. 2010.

COSTA, L. M. Notícias esportivas. Entre o jornalismo e a literatura. Anais do Silel, Uberlândia, v.2, n.2, p. 1-16, 2011.

DAMO, A. S. Dom, amor e dinheiro no futebol espetáculo. Revista Brasileira de Ciências Sociais, São Paulo, v. 23, n. 66, fevereiro, 2008. 
DAMO, A. S. Futebol e estética. São Paulo em Perspectiva, São Paulo, v.15, n.3, p. 82-91, 2001.

DUARTE, A. Torcida gravita em torno de Ronaldo. Folha de São Paulo. São Paulo, 04 mai. 2009. p. D6.

FOLHA DE SÃO PAULO. Abatido, São Paulo se agarra à Libertadores. São Paulo, 21 abr. 2009. p. D4.

FOLHA DE SÃO PAULO. Corinthians e Ronaldo ferem São Paulo. São Paulo, 13 abr. 2009. p.D6.

FOLHA DE SÃO PAULO. Domingos ganha missão de parar o astro. São Paulo, 03 mai. 2009. p. D6b.

FOLHA DE SÃO PAULO. Ronaldo devolve provocação com gol e deboche. São Paulo, 20 abr. 2009. p. D3.

FOLHA DE SÃO PAULO. Ronaldo fez a diferença. São Paulo, 27 abr. 2009. p.1.

FOLHA DE SÃO PAULO. Ronaldo, sem gol, exalta sua atuação. São Paulo, 23 mar. 2009. p. D1.

GALDIERI, P.; ASSIS, T. No mata-mata, Corinthians se vinga. Folha de São Paulo. São Paulo, 20 abr. 2009. p. D1.

GALDIERI, P.; BUENO, R. Ronaldo faz, e Pacaembu delira. Folha de São Paulo. São Paulo, 12 mar. 2008. p.D1.

GALDIERI, P.; CALCIOLI, R. Ronaldo encosta Corinthians no título. Folha de São Paulo. São Paulo, 27 abr. 2009. p. D1.

GALDIERI, P. Felipe falha e ofusca a noite de Ronaldo. Folha de São Paulo. São Paulo, 26 mar. 2009. p. D2.

GASTALDO, E. L. "O país do futebol” mediatizado: mídia e Copa do Mundo no Brasil. Sociologias, Porto Alegre, ano.11, n.22, p. 352-369, jul/dez, 2009.

GASTALDO, E. L. "Os campeões do século": notas sobre a definição da realidade no futebol - espetáculo. Revista Brasileira de Ciências do Esporte, Campinas, v. 22, n. 01, p. 105-124, setembro, 2000.

GIGLIO, S. Futebol: mitos, ídolos e heróis. 2007. 162 f. Dissertação (Mestrado em Educação Física) - Curso de Educação Física, Departamento de Educação Física, UNICAMP, Campinas - SP, 2007.

GURGEL, A. Desafios do jornalismo na era dos megaeventos esportivos. Motrivivência, Florianópolis, ano.21, n.32/33, p. 193-210, jun/dez, 2009. 
HELAL, R. A construção de narrativas de idolatria no futebol brasileiro. Alceu, Rio de Janeiro, v. 4, n. 7, p. 19-36, jul./dez. 2003.

HELAL, R.; SANTORO, M. A.; SOARES, A. J. Futebol, imprensa e memória. Revista Fronteiras - Estudos midiáticos, São Leopoldo, v.6, n.1, p. 61-78, jan/jun. 2004.

HELAL, R.; SOARES, A. J. A invenção do país futebol: Mídia, raça e idolatria. Rio de Janeiro: Mauad, 2001.

KFOURI, J. Ronaldo titular e predestinado. Folha de São Paulo. São Paulo, 12 mar. 2009. p.D3.

MARQUES, J. C. O mito construído, destruído e restituído - o caso cíclico de Ronaldo fenômeno. Intercom/2005 - Congresso Brasileiro, Rio de Janeiro, 28. Setembro 2005, Anais..., Rio de Janeiro - RJ, Brasil, 2005.

MOREIRA, T. S.; MARCHI JUNIOR, W. Mídia impressa: Construção de uma preferência nacional esportiva em questão. I Seminário nacional sociologia e política - UFPR, 2009, Curitiba.

MULLER, L. O herói: todos nascemos para ser heróis. São Paulo: Cultrix, 1987.

NEGREIROS, P. L. A invenção corinthiana - Rio, 5 de dezembro de 1976. Aurora, São Paulo, v.9, n.1, p. 114-127, 2010.

PRONI, M. W. Esporte-espetáculo e futebol-empresa. 1998. 262 f. Tese (Doutorado em Educação Física) - Faculdade de Educação Física da Universidade Estadual de Campinas, Campinas. 1998.

RIBEIRO, L. C. Futebol: por uma história política da paixão nacional. História: questões e debates, Curitiba, v. 57, n.2, p. 15-43, jul./dez. 2012.

RÚBIO, K. A identidade do atleta e sua relação com o mito do herói. Congreso de La Sociedad Iberoamericana de Psicología del Deporte, 3. Bogotá, Anais... Bogotá p. 63-75, 2010.

RÚBIO, K. N. O imaginário esportivo contemporâneo. São Paulo: Casa do Psicológo, 2001.

RÚBIO, K. O imaginário da derrota no esporte contemporâneo. Psicologia e Sociedade, Porto Alegre, v.18, n.1, p. 86-91, jan/abr, 2006.

SANTOS, N.; CAPRARO, A. M. O futebol em Nelson Rodrigues: crônica esportiva e identidade nacional. Revista Eletrônica Cadernos de História, v.9, n.1, p. 79-97, abr. 2012.

SILVA, G. M. A crítica ao SUS no jornal Folha de São Paulo. 2010. 132 f. Dissertação (Mestrado em Psicologia) - Departamento de Psicologia, UFB, Uberlândia-MG. 2010.

SOARES, A. J. A imprensa e a Memória do futebol brasileiro. Revista Portuguesa de Ciências do Desporto, Porto, v.7, n.3, dez, 2007. 
Recebido em: 26/02/2015

Revisado em: 14/10/2015

Aprovado em: 05/03/2016

Endereço para correspondência:

profevertoncavalcanti@gmail.com

Everton De Albuquerque Cavalcanti

Universidade Federal do Paraná, Departamento de Educação Física.

Rua Coração de Maria, 92 - BR 116 km 95

Campo Comprido

80215-370 - Curitiba, PR - Brasil 